\title{
Modeling co-seismic thermal infrared brightness anomalies in petroliferous basins surrounding the North and East of the Qinghai-Tibet Plateau
}

\author{
Xin Zhang ${ }^{{ }^{*}}$, and LiFeng Zhang ${ }^{2}$ \\ ${ }^{1}$ Key Laboratory of Earthquake Monitoring and Disaster Reduction Technology, Guangdong Earthquake Agency, Guangzhou 510070, China; \\ ${ }^{2}$ Qinghai Earthquake Agency, Xining 810001, China \\ Key Points: \\ - Co-seismic brightness anomalies surrounding the North and East of the Qinghai -Tibet Plateau are reviewed \\ - Co-seismic greenhouse gas leaking is suggested to cause brightness temperature anomalies \\ - A new model of thermal emission based on six earthquakes occurred in four petroliferous basins is presented
}

Citation: Zhang, X., and Zhang, L. F. (2020). Modeling co-seismic thermal infrared brightness anomalies in petroliferous basins surrounding the North and East of the Qinghai-Tibet Plateau. Earth Planet. Phys., 4(3), 296-307. http://doi.org/10.26464/epp2020029

\begin{abstract}
Co-seismic gas leakage usually occurs on the edge of seismic faults in petroliferous basins, and it may have an impact on the local environment, such as the greenhouse effect, which can cause thermal infrared brightness anomalies. Using wavelet transform and power spectrum estimation methods, we processed brightness temperature data from the Chinese geostationary meteorological satellite FY-C/E. We report similarities between the co-seismic thermal infrared brightness (CTIB) anomalies before, during and after earthquakes that occurred at the edges of the Sichuan, Tarim, Qaidam, and Junggar basins surrounding the North and East of the Qinghai-Tibet Plateau in western China. Additionally, in each petroliferous basin, the area of a single CTIB anomaly accounted for $50 \%$ to $100 \%$ of the basin area, and the spatial distribution similarities in the CTIB anomalies existed before, during and after these earthquakes. To better interpret the similarities, we developed a basin warming effect model based on geological structures and topography. The model suggests that in a petroliferous basin with a subsurface gas reservoir, gas leakage could strengthen with the increasing stress before, during, and even after an earthquake. The accumulation of these gases, such as the greenhouse gases $\mathrm{CH}_{4}$ and $\mathrm{CO}_{2}$, results in the $\mathrm{CTIB}$ anomalies. In addition, we conclude that the CTIB anomalies are strengthened by the high mountains (altitude $5000 \mathrm{~m}$ ) around the basins and the basins' independent climatic conditions. This work provides a new perspective from which to understand the CTIB anomalies in petroliferous basins surrounding the North and East of the Qinghai-Tibet Plateau.
\end{abstract}

Keywords: co-seismic thermal infrared brightness (CTIB); relative power spectrum (RPS); gas leakage; basin warming effect

\section{Introduction}

Co-seismic heat radiation is a common phenomenon that is usually found in areas with the largest linear structures and fault systems, such as those in the central Asian active seismic region, Iran, Italy, and India (Tronin, 1996; Ouzounov and Freund, 2004; Choudhury et al., 2006; Qin et al., 2012; Piroddi et al., 2014). Previous studies have shown that co-seismic heat radiation could be detected before an earthquake (Tronin, 2000a, b). Tronin (2000a) reported an initial thermal infrared brightness anomaly observed by satellite prior to earthquakes and discussed co-seismic anomalies during several minor earthquakes of $M_{\mathrm{L}} 3.6-5.5$ in northeastern China. Tronin (2000b) and other researchers have also reported that Japanese land surface temperature (LST) anomalies had

Correspondence to: X. Zhang, zxdqwl@163.com

Received 26 OCT 2019; Accepted 11 FEB 2020.

Accepted article online 17 APR 2020.

(C) 2020 by Earth and Planetary Physics. shorter precursor times ( 1 week) and higher amplitudes. These studies are significant because they further confirmed that LST anomalies are associated with lineaments and faults that are integral parts of Earth's seismicity. However, the magnitudes of these earthquakes were much smaller than those in other areas of China, especially in the area of the Qinghai-Tibet Plateau surrounded by several petroliferous basins.

Previous studies of earthquake series have used a Robust Estimator of Thermal Infrared Anomalies index (Filizzola et al., 2004; Corrado et al., 2005; Aliano et al., 2008; Pergola et al., 2010). Saraf et al. (2012) focused on ten different M5.8-6.6 earthquakes that occurred from June 2002 to June 2006 in Iran, and Choudhury et al. (2006) investigated the Bam M6.6 and Zarand M6.4 earthquakes. They reported 5-10 ${ }^{\circ} \mathrm{C}$ LST anomalies $\sim 6$ days before the earthquake. The maximum observed amplitude of the LST anomaly was $13^{\circ} \mathrm{C}$, although it was based on visual features of LST images rather than on statistical methods. Rawat et al. (2011) presented a similar analysis of the M5.9 Vrancea (Romania) earthquake and the 
M5.1 Yamnotri (India) earthquake. The anomalies were in the range of $5-10{ }^{\circ} \mathrm{C}$, appearing $\sim 1$ week before these two earthquakes. However, the key point of their studies was their use of outgoing longwave radiation anomalies as a proxy for and in association with the LST anomalies. Co-seismic thermal infrared radiation depends on temperature and the greenhouse effect. Thus, any earthquake-induced co-seismic thermal anomalies may be related to the greenhouse effect.

The greenhouse effect is the main component in forming co-seismic thermal infrared brightness (CTIB) anomalies. Greenhouse gases such as carbon monoxide $(\mathrm{CO})$ and methane $\left(\mathrm{CH}_{4}\right)$ mixing into the air could cause the air temperature to rise nearly $3-6{ }^{\circ} \mathrm{C}$ under polarization of the atmospheric electric field (Qiang ZJ et al., 1999). It has also been confirmed that mixed gases containing $\mathrm{CH}_{4}$ could cause the temperature to rise via solar radiation or transient electric fields (Qiang ZJ et al., 1994, 1999). Scholars have studied how the gases, including $\mathrm{CO}_{2}, \mathrm{CH}_{4}$, and $\mathrm{CO}$, strengthen climate warming and the temperature increase before and after an earthquake (EQ) occurs (Tronin, 2009; Zhang YS et al., 2010; Lu X et al., 2016; Anderson et al., 2017; Jiao ZH et al., 2018). However, it is not clear where these gases come from and what kind of crustal structure or basin topography has a greater effect on the CTIBs. More consideration is needed to establish the presence of CTIB anomalies with high statistical confidence before their probable mechanisms can be investigated, as there are points of uncertainty associated with the anomalies themselves (Bhardwaj et al., 2017a), such as (1) the relationship between these co-seismic anomalies and geological characteristics and (2) how confidently they can be detected via remote sensing. In the following sections, we attempt to analyze these concerns from the perspective of similar basins' CTIBs. We focus on those basins specifically that are producing oil and gas. The scope of our present model is a comprehensive overview of CTIB basin anomalies; we discuss them in terms of how their geographic and geological characteristics combine to explain the observed phenomena.
To identify the possible mechanism between gas leakage and CTIBs, we utilize as examples four petroliferous basins in western China. Wavelet transform and power spectrum estimation are used to analyze the CTIB data of the Jiuzhaigou $M_{\mathrm{S}} 7.3$ EQ (JZGE) and Wenchuan $M_{S} 8.0 \mathrm{EQ}$ (WNCE) that occurred at the edge of the Sichuan basin, the Yutian $M_{\mathrm{s}} 7.3 \mathrm{EQ}$ (YUTE) and Xinyuan $M_{\mathrm{s}} 6.6 \mathrm{EQ}$ (XNYE) that occurred at the edge of the Tarim basin, the Jinghe $M_{\mathrm{S}} 6.6 \mathrm{EQ}$ (JNHE) that occurred at the edge of the Junggar basin edge, and the Haixi $M_{5} 6.6 \mathrm{EQ}$ (HAXE) that occurred at the edge of the Qaidam basin. The results show that there are similar spatial variation characteristics in the CTIB anomalies during these EQs. To explain these similarities among the events, we propose a basin-warming-effect model in which we also take into consideration terrain conditions around these basins' edges.

\section{Data and Methods}

The initial data used in this paper were collected by the two satellites FY-2C and FY-2E, downloaded from the National Satellite Meteorological Center (http://satellite.nsmc.org.cn/portalsite/default.aspx). The FY-2C satellite was launched on October 19, 2004, with a fixed point at $105^{\circ} \mathrm{E}$ above the equator; the FY-2E satellite was launched in 2008 , its orbit also fixed at $105^{\circ} \mathrm{E}$ above the equator, with an entire coverage area of $50^{\circ} \mathrm{N}-50^{\circ} \mathrm{S}$ and $55^{\circ} \mathrm{W}-155^{\circ} \mathrm{E}$. The resolution of the infrared brightness temperature is $5 \mathrm{~km}$. Since November 2009, the FY-2E has provided effective data service. The observation channels parameter of the FY-2E satellite can be divided into 5 bands. The most suitable one is the middle band, that is, the intermediate infrared 6.32-7.55 and 3.59-4.09. Brightness temperature observation is taken once an hour to obtain successive data. For a certain pixel, the position of the satellite and propagation path of thermal radiation is almost fixed. That is why we used data from geostationary meteorological satellites rather than high-resolution polar orbit satellites.

The spatial coverage of the data used is the three areas shown in Figure 1 . We applied these data in calculating the relative power

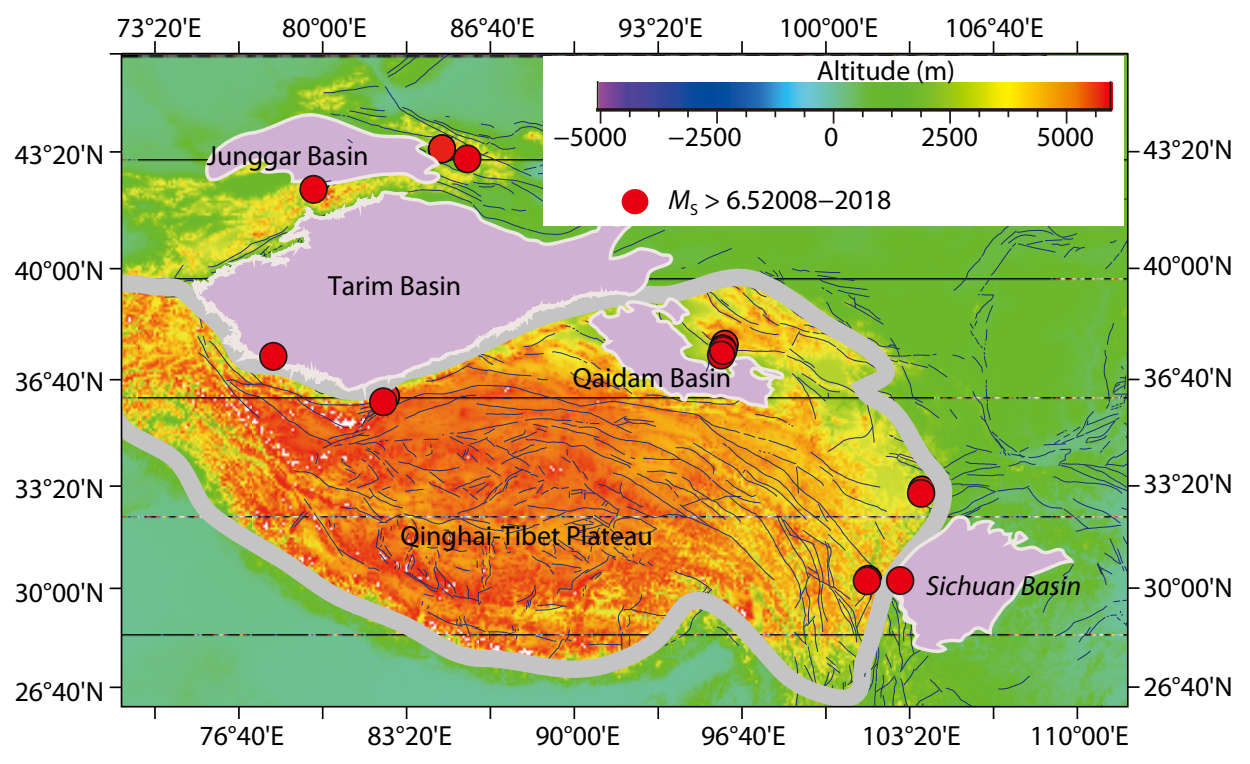

Figure 1. Topographic map of four basins around the Qinghai-Tibet Plateau. The four petroliferous basins are located on the eastern or northern sides of the Qinghai-Tibet Plateau. The red dots represent the epicentral positions of EQs $\left(M_{\mathrm{S}}>6.5\right)$. 
spectrum (RPS). Brightness temperature time series with a time resolution of one day were gathered for every pixel. For a certain pixel, the position of a satellite and the propagation path of the thermal radiation are almost fixed. Thus, data from a geostationary meteorological satellite rather than a polar-orbiting satellite are used in this work.

Radiation from the sun in the daytime can cause increases or relatively sharp perturbations in the brightness temperature observed by satellites. To avoid this effect, brightness temperature data from 00:00 to 04:00 LT are used. We used the mean value of five chosen brightness temperature data points as the observed daily values. To extract information from more frequencies and to analyze anomalies by comparing them to normal states, the length of the daily brightness temperature series was set to three years. However, some preprocessing needs to be conducted on the brightness temperature series before using the wavelet transform method to detect anomalies. When some pixels were covered by clouds, the brightness temperatures of these areas actually reflected the temperatures of the cloud tops, which were much lower than the corresponding LST under the clouds.

Wavelet transform can decompose the time series data into mutually independent frequency components almost without loss of information. Each component has a different dominant factor, making the physical meaning much clearer than is possible using other methods. The wavelet transform method is used to eliminate low-frequency annual and seasonal components and high-frequency random components such as local meteorological conditions and human activities (Jiao ZH et al., 2018). Continuous longwave radiation data should include the basic temperature field of the Earth as well as annual and daily temperature fields. Temperature changes, however, are also caused by clouds, rain, cold and hot air flow, topography, and other factors (including EQs) as well as varying longwave radiation information. Longwave radiation can be removed by using a wavelet transform, which omits the low-pass part of the seventh order of the wavelet by subtracting the low-pass component of the second-order from the low-pass component of the seventh order of the wavelet. This means that information on the intermediate band is retained, and information on the high and low frequencies is omitted. Besides, the impact of the temperature changes caused by rain clouds and cold or hot air currents usually lasts only a few hours to several days. This kind of information can be weakened by the wavelet transform process in which the high-pass part of the second-order of the wavelet is omitted.

We adopt the same approaches to processing data as those in Xie et al. (Xie T et al., 2013; Xie T and Ma WY, 2015) and Lu X et al. (2016). The process is divided into the following three steps.

First, we used the wavelet transforms to separate the initial brightness anomaly. The db8 wavelet basis wavelet transform method that we selected from Daubecheies was determined to be optimal after many experiments. Based on db8, the wavelet basis was divided along a seven-order long-period wavelet scale. We extracted a trend component with a period of about years or more in the brightness temperature of every pixel, and these results showed an obvious annual cycle.
Second, we obtained the power spectrum estimate by using brightness temperature waveform data to calculate the power spectrum with the Fast Fourier Transform method. In the transformation, a short time period anomaly was considered with a window length of 64 days, and then with a step length of 1 day; six frequencies were obtained: $64,32,21,16,13$, and 11 days, respectively.

To determine the difference between the EQ times and other periods, we calculated the RPS value of each pixel $\left(0.05^{\circ} \times 0.05^{\circ}\right)$ using the following formulas:

$$
\begin{gathered}
A_{i k}=\frac{1}{l} \sum_{j=1}^{l} W_{i j k}, \quad(i=1,2, \cdots, n ; k=1,2, \cdots, m), \\
R_{i j k}=\frac{W_{i j k}}{A_{i k}}, \quad(i=1,2, \cdots, n ; j=1,2, \cdots, l ; k=1,2, \cdots, m) .
\end{gathered}
$$

In Formulas (1) and (2), $m$ is the total number of pixels, and $n$ is the number of frequency points. $i, j$, and $k$ represent the pixel, day, and frequency, respectively. The $W_{i j k}$ is the power spectrum of each pixel per day per frequency; $A_{i k}$ is the average of every pixel per frequency for 1 day, and $R_{i j k}$ is the everyday RPS of every pixel per frequency.

Finally, we calculated the background value and standard deviation. The background value was the average of the RPS on the same day of each year, and the standard deviation calculation was based on the background value. The calculation process was as follows:

$$
\begin{gathered}
\overline{A_{j}}=\frac{\sum_{k=1}^{k=10} \sum_{i=1}^{i=121} R_{i j k}}{N}, N=1210, \quad(1 \leq j \leq 365), \\
B_{j}=\sqrt{\frac{\sum_{k=1}^{k=10} \sum_{i=1}^{i=121}\left(R_{i j k}-\overline{A_{i}}\right)^{2}}{N}}, N=1210, \quad(1 \leq j \leq 365) .
\end{gathered}
$$

In these formulas, $j$ and $k$ represent days and years, respectively. $\overline{A_{j}}$ represents the everyday average of RPS for ten years, and $B_{j}$ represents the everyday standard deviation. Ten years of data are used, and every year is presumed to be 365 days. Every $0.5^{\circ} \times 0.5^{\circ}$ range has 121 pixels (a matrix of $11 \times 11$ ), so the time range of 10 years has 1210 pixels.

Taking the data series of 2014-2017 as an example, Figure 2 shows the process detail about the original brightness temperature (BT in Figure 2) data. The wavelet transforms of the four years from the epicenter $\left(33.2^{\circ} \mathrm{N}, 103.8^{\circ} \mathrm{E}\right)$ as well as the seventh-order wavelet scale (Figure 2a2) annual variations are shown. The Earth's annual temperature field influence is eliminated by removing the seventh-order long-period component of the wavelet scale. Similarly, since the cloud duration/rainy periods and temperature change caused by the cold/hot airflow are relatively short and usually last for a few hours to a few days, their influence should be significantly reduced or eliminated by removing the seven-order wavelet component (Figure 2b1).

Wavelet transform is widely used in geophysics, seismic prospecting, etc. The conflict between time resolution and frequency resolution can be well resolved by changing the shape of the time-frequency window. Thus, the wavelet transform is localized both in time and in the frequency domain. The high power caused by 

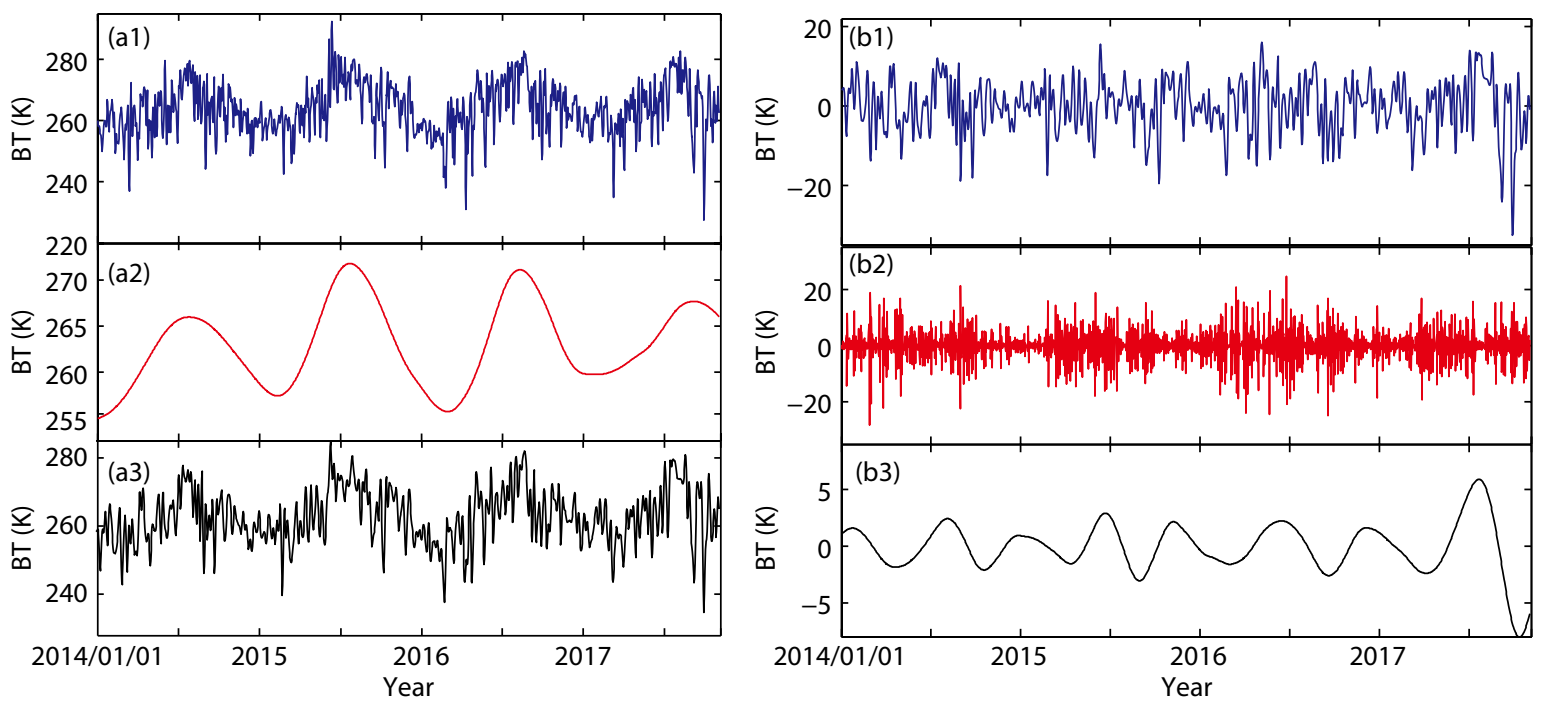

Figure 2. The result of the wavelet transformation of the brightness temperature (BT). The $Y$-axis represents BT. Figures b1-b3 represent original BT data, and 7-order and 2-order results after wavelet decomposition, respectively. Figures $\mathrm{c} 1-\mathrm{c} 3$ represent the product of wavelet process, and 1-scale and 7-scale of wavelet residuals signal, respectively. The red line represents the result of the relative difference between the separation results, which would be abandoned. The black line represents the result that was separated from the original data.

sharp variations of low cloud-top temperature in power spectrum analysis is removed after cloud elimination. Temperature increase before earthquakes often lasts longer than short-time fluctuations. Thus, their power could possibly be presented at different frequencies. To reflect the difference between the power spectrum of the long-wave radiation before and after the earthquake and that of other periods, we processed the relative amplitude of the power spectrum of each pixel at all frequencies and obtained the spatial distribution of the time-frequency relative changes in the power spectrum.

In this study, RPS reflects the distribution of the energy of the random signal; it reveals useful information such as the hidden periodicity and the near-spectral peaks in the signal. The dominant frequency and amplitude can be obtained by power spectrum estimation. The rising of the RPS curve means that the satellite has detected an increase of thermal radiation. The purpose of this work is to seek the similarities and differences in the power spectra of sub-longwave radiation variations before and after EQs in basins. The mathematical calculation method used in this paper is both sophisticated and general, and its process is simple. The calculated time/frequency spatial data are scanned in full space-time and full frequency bands to find the corresponding frequency (i.e., typical period), time, and regional position with which the larger amplitude changes.

\section{Results and Discussion}

\subsection{CTIB Temporal and Spatial Variations}

Analyzing the daily CTIB data before the JZGE, we found that the CTIB increased significantly along the Longmenshan fault in July 2017 (Figure 3). Combined with the specific tectonic distribution, our conclusion is that the epicenter of JZGE was located on the edge of the Sichuan basin, which is also on the edge of the CTIB anomaly area. In the time series, the CTIB anomaly gradually reduced to a minimum in early August and then slightly increased on August $8^{\text {th }}$, when the JZGE occurred. Afterwards, the CTIB anomaly lasted until August $14^{\text {th }}$ but with a weakening trend. Finally, the CTIB anomaly contracted in the southern Longmenshan fault and disappeared completely in the middle of September.

Similar to JZGE, the WNCE also occurred in the western Sichuan basin in 2008, and its CTIB anomaly lasted two months before and after the EQ and was distributed mainly in the Sichuan basin. Also, the CTIB's strength and coverage increased to its maximum level in late May, after the WNCE occurred (Figure 4). The main CTIBs of both WNCE and JZGE were distributed in the central Sichuan basin, which is full of oil and gas.

Both of these CTIBs experienced extension from the northern Longmenshan fault to the Sichuan basin and eventually contracted to the southern Longmenshan fault. On the one hand, the CTIB anomaly of JZGE was distributed along the Longmenshan fault. Similarly, the main part of the JZGE's CTIB was distributed primarily along the northwestern edge of the Sichuan basin (Figure $5 \mathrm{~b}$ ). The maximum areas of the two CTIBs reached $12 \times 10^{4} \mathrm{~km}^{2}$ and 8 $\times 10^{4} \mathrm{~km}^{2}$, respectively, for WNCE and JZGE, and their CTIB proportions of the basins reached $66 \%$ and $50 \%$ (Figure $5 \mathrm{a}$ and $5 \mathrm{~b}$ ). On the other hand, the CTIB anomaly of WNCE was bounded by the Longmenshan fault but was mainly distributed in the northern part of the Sichuan basin. Geographically, WNCE occurred on the most extreme western corner of the CTIB anomaly (Figure 5a), and the spatial distribution of the CTIB anomalies in these two EQs depended on the spatial position of the Longmenshan fault. We observe that the WNCE's anomaly would be almost the same as the JGZE's CTIB anomaly if it were moved westward until its boundary passed through the Longmenshan fault.

Earthquake-associated CTIB anomalies have appeared not only on the periphery of the Sichuan basin; they have also been detected in the Tarim basin as well as in other petroliferous basins after large EQs. Like the CTIB anomaly associated with JZGE, the CTIB anomalies associated with YUTE, XNYE, JNHE, and HAXE also ap- 

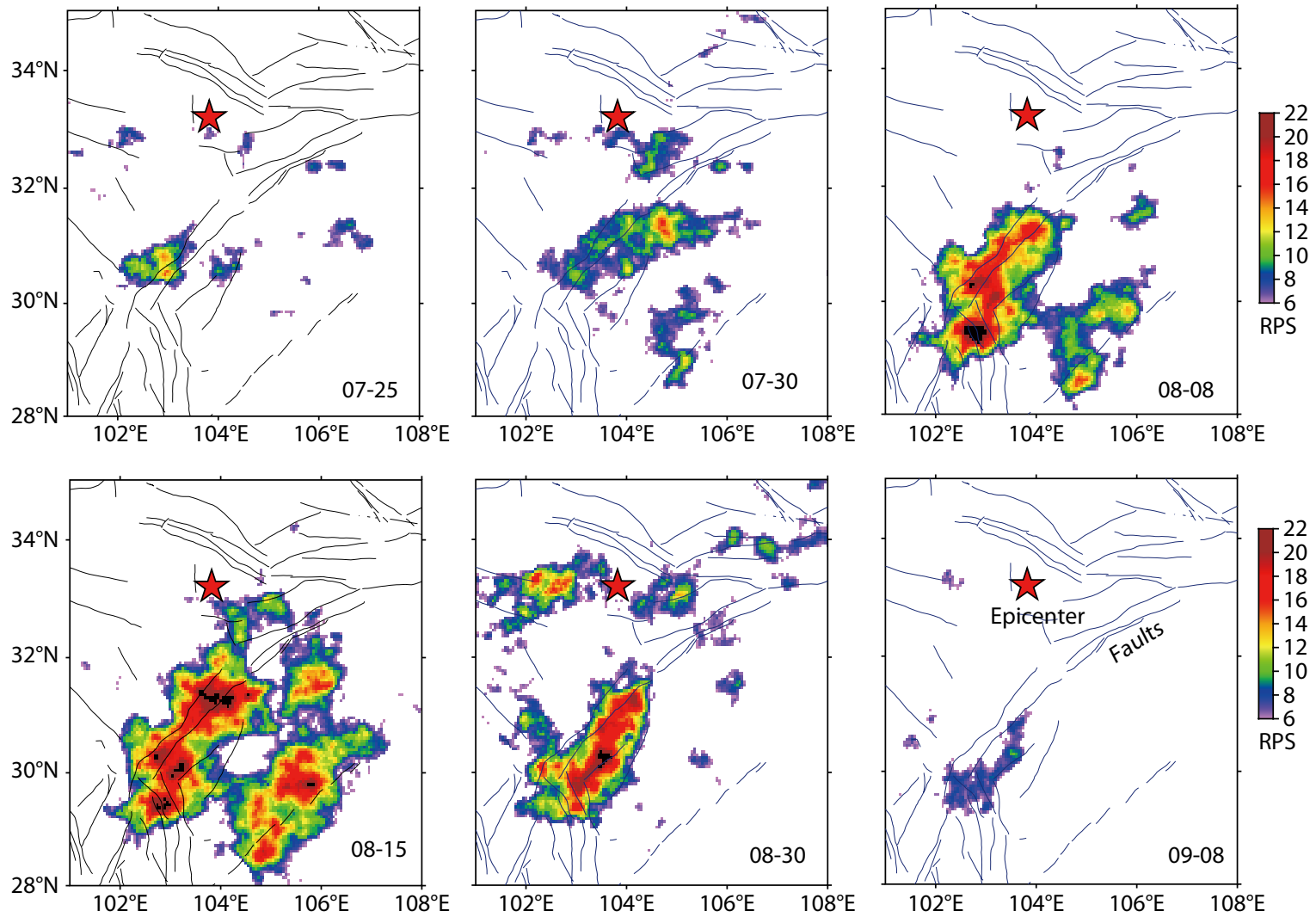

Figure 3. Spatiotemporal evolution of the CTIB anomaly before and after the JZGE, from July to September 2017. The hexagon represents the epicentral location of the JZGE, and the black line represents active faults in the area.
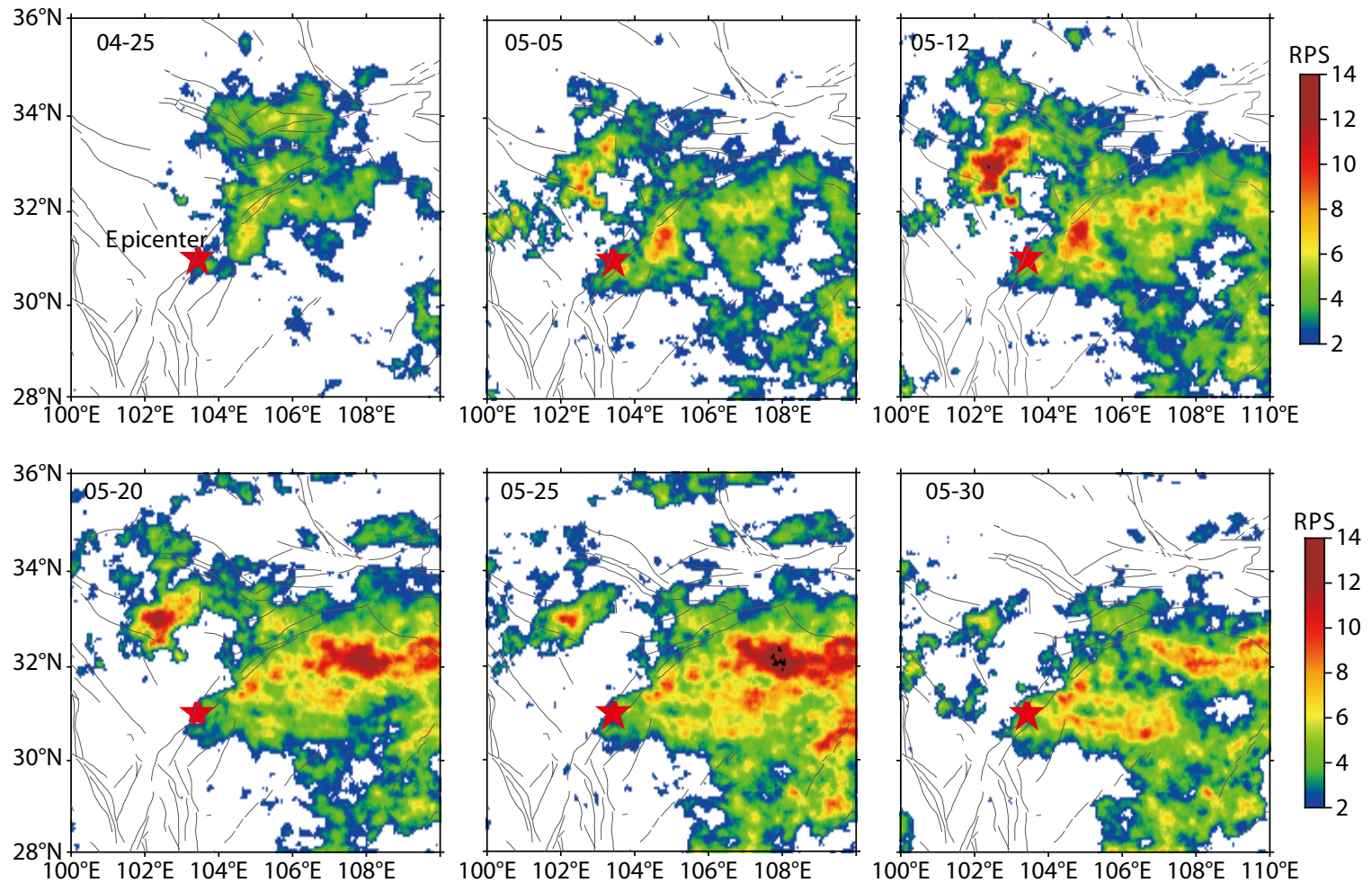

Figure 4. Spatiotemporal evolution of the CTIB anomaly before and after the WECE in 2008. The hexagon represents the epicentral location of the WECE, and the black line represents active faults in the area. 


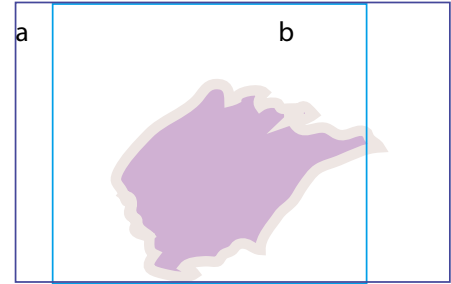

Sichuan Basin
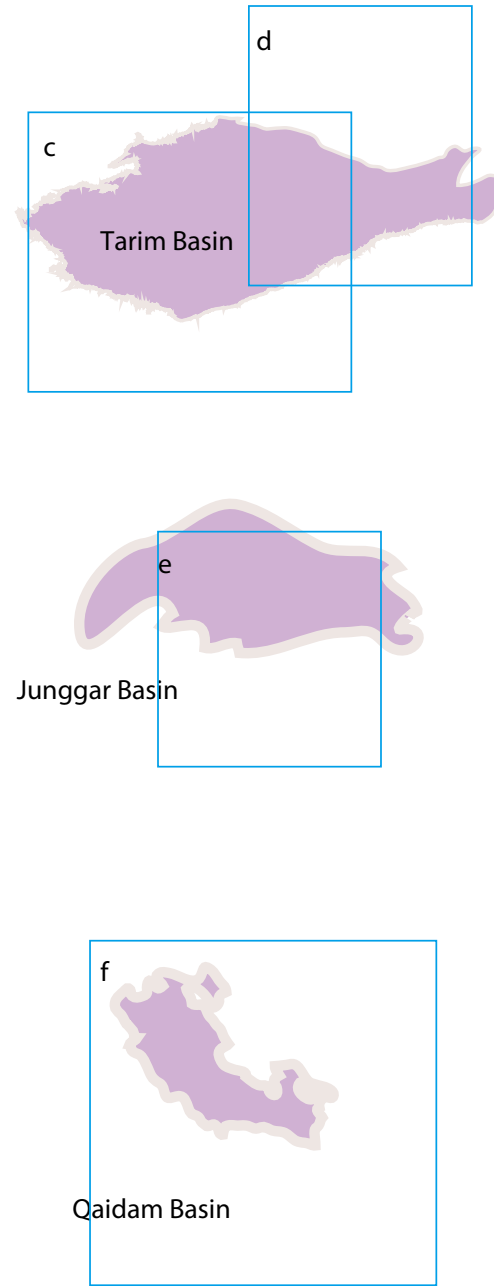
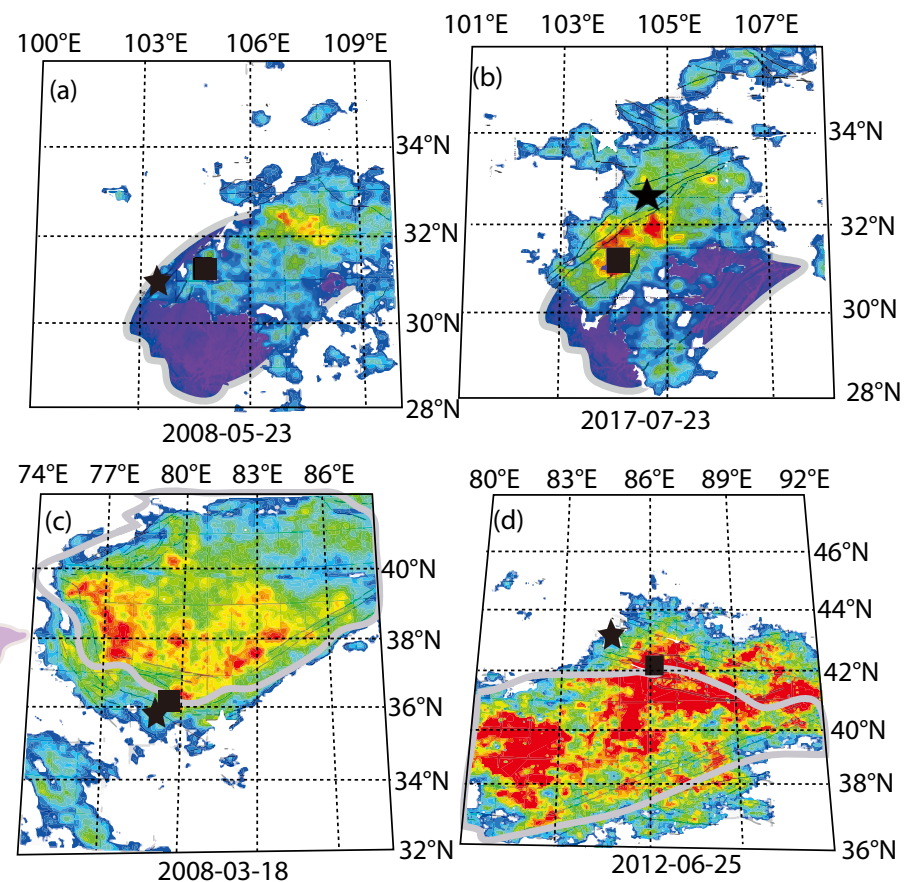

(e)
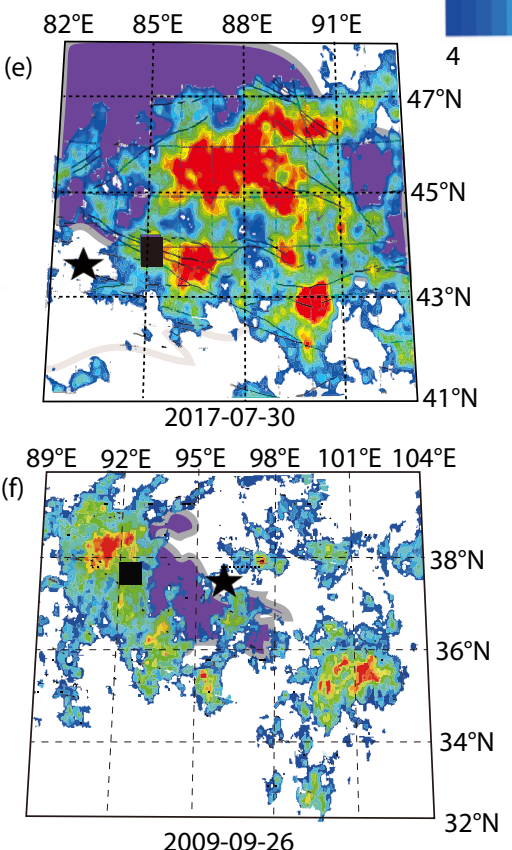

(a) WNCE $M_{\mathrm{s}} 8.0$

(b) JZGE $M_{\mathrm{s}} 7.0$

(c) YUTE $M_{\mathrm{S}} 7.3$

(d) XNYE $M_{\mathrm{S}} 6.6$

(e) JNHE $M_{\mathrm{s}} 6.6$

(f) HAXE $M_{\mathrm{s}} 6.6$

Figure 5. Spatial distributions of CTIB anomalies of six EQs in four basins. (a)-(f) are formed by the same method as in Figure 3-4. The black square represents the region whose temporal data were used to calculate RPS.

peared, migrated, and developed in the same way (Figure 5). In Table 1 we list several similar EQs with their CTIB anomalies. The spatial distribution of the CTIB anomaly that follows that of YUTE on March 21st, 2008 is shown in Figure 5c; the spatial distribution of the CTIB anomaly that follows that of XNYE on June 30th 2012 is shown in Figure $5 \mathrm{~d}$. For the two EQs YUTE and XNYE, the maximum areas of their CTIBs reached $55 \times 10^{4} \mathrm{~km}^{2}$ and $60 \times 10^{4} \mathrm{~km}^{2}$, respectively, and the CTIB proportions of the basin reached $100 \%$ and $83 \%$. The two CTIB anomalies throughout the Tarim basin also had different seismogenic structures. This phenomenon reveals that different EQ seismogenic structures may have similar
CTIB anomalies, which is similar to what was observed in the two EQs occurring in the Sichuan basin (Figure 5a, Figure 5b).

JNHE (Figure 5e) occurred at the edge of the Junggar basin, following a CTIB anomaly. As shown in Table 1 and Figure 5e, the maximum area of the CTIB reached $25 \times 10^{4} \mathrm{~km}^{2}$, and the CTIB proportion of the basin reached $100 \%$. Similarly, HAXE occurred at the eastern edge of the Qaidam basin. As shown in Figure 4f, the CTIB anomaly associated with HAXE occupied $65 \%$ of the entire basin. We note that the temporal and spatial characteristics of the CTIB anomaly evolution process associated with JNHE and HAXE are similar to those of the anomalies associated with WNCE and 
Table 1. The features of the time series curves and CTIBs associated with the basins for six earthquakes.

\begin{tabular}{|c|c|c|c|c|c|c|c|c|c|}
\hline Event & Date & Basin & Location & $\begin{array}{l}\text { Earthquake } \\
\text { magnitude }\end{array}$ & $\begin{array}{l}\text { Peak value } \\
\text { (times) }\end{array}$ & $\begin{array}{l}\text { Longer than } \\
\text { 2nd (day) }\end{array}$ & $\begin{array}{l}\text { Maximum } \\
\text { area }\left(\mathrm{km}^{2}\right)\end{array}$ & $\begin{array}{l}\text { Proportion of } \\
\text { the basin (\%) }\end{array}$ & $\begin{array}{c}\text { Abnormal position } \\
\text { of the basin }\end{array}$ \\
\hline WNCE & $2008 / 5 / 12$ & Sichuan & $\begin{array}{l}30.95^{\circ} \mathrm{N} \\
103.4^{\circ} \mathrm{E}\end{array}$ & Ms7.3 & 7.4 & 81 & $12 \times 10^{4}$ & 66 & $\begin{array}{l}\text { Western and } \\
\text { outside }\end{array}$ \\
\hline JZGE & $2017 / 8 / 8$ & Sichuan & $\begin{array}{l}33.2^{\circ} \mathrm{N} \\
103.8^{\circ} \mathrm{E}\end{array}$ & Ms8.0 & 11.5 & 73 & $8 \times 10^{4}$ & 50 & $\begin{array}{c}\text { Northwestern and } \\
\text { outside }\end{array}$ \\
\hline YUTE & $2008 / 3 / 21$ & Tarim & $\begin{array}{l}35.6^{\circ} \mathrm{N} \\
81.6^{\circ} \mathrm{E}\end{array}$ & Ms7.0 & 9.8 & 105 & $55 \times 10^{4}$ & 100 & Inner and edge \\
\hline XNYE & $2012 / 6 / 30$ & Tarim & $\begin{array}{l}43.4^{\circ} \mathrm{N} \\
84.8^{\circ} \mathrm{E}\end{array}$ & Ms6.6 & 16 & 75 & $60 \times 10^{4}$ & 83 & $\begin{array}{l}\text { Eastern and } \\
\text { outside }\end{array}$ \\
\hline JNHE & $2017 / 8 / 9$ & Junggar & $\begin{array}{l}44.27^{\circ} \mathrm{N} \\
82.89^{\circ} \mathrm{E}\end{array}$ & Ms6.6 & 13.5 & 52 & $25 \times 10^{4}$ & 100 & Inner and edge \\
\hline HAXE & $2009 / 8 / 28$ & Qaidam & $\begin{array}{l}37.6^{\circ} \mathrm{N} \\
95.8^{\circ} \mathrm{E}\end{array}$ & Ms6.6 & 9.7 & $\sim 40$ & - & 65 & Inner and edge \\
\hline
\end{tabular}

JZGE in the Sichuan basin. We also note that the seismogenic structures of XNYE and JNHE are between the Junggar and Tarim basins (Figure 1 and Figure 5), while the CTIB anomaly of XNYE is distributed in the Tarim basin near high mountains. Therefore, we conclude, based on the parallel features of these thermal radiation source anomalies that have been observed before and after EQs in these petroliferous basins, that these anomalies have a significance that cannot be ignored.

\subsection{RPS Time Series Curves}

The RPS value of the $0.5^{\circ} \times 0.5^{\circ}$ area of anomalous significance (the black square shown in Figure 5) was extracted, and then the time series curve was calculated (Figure 6). There are two major principles for selecting the black square: (a) the area must be near the seismogenic fault and (b) it must be in the high-value area of the CTIB. The background value refers to the average RPS value in the past 10 years (or longer, if more data were available); the standard deviation is calculated by the method in Formulas (3) and (4), shown with green line in Figure 6 . In the RPS series curve, values exceeding 6 times the background value are indicated by the red line and the yellow area; we interpret this figure as strongly suggesting that the peak periods are likely to be related to EQs or other great geotectonic activity events.

Comparing the relationship between CTIB occurrence and the time of EQ occurrence, we conclude that petroliferous basins and seismological structures may cause gas leakages that lead to CTIB anomalies. We take the RPS of JZGE as an example; it exhibits seven peaks before and after the EQ (Figure 6e). The occurrence closest to the event is six days before the EQ (on August $2^{\text {nd }}$ ) and has an amplitude that is 11.5 times higher than the background value, as well as RPS $=6$. During the entire process, the duration time of the anomalous magnitude is almost 40 days, 8 times longer than the background value. The RPS amplitude peak value is at its minimum at the time when JZGE is occurring, but it is unclear whether it would change with the large amplitudes of the other times of the EQs in Table 1. We, therefore, estimate it by calculating two sets of background values and the standard deviation of the data.

Considering the relationship between the process of CTIB and the time of JZGE occurrence, it is found that, before July, the two sets of background and standard deviation curves almost coincide with each other, indicating that the data had a trivial effect on the background value between January and July, 2017. Besides, compared with the rise in the data observed from July to August, the increase from May to June was relatively low, which indicates that the amplitudes of the past data do not change much when the JZGE was occurring. By the beginning of September, the RPS variation caused by the JZGE had disappeared.

RPS curves of these six EQs are shown in Figure 6. The RPS of XNYE is similar to that of JZGE, with the high value of the RPS lasting for a period after the EQ. The reason may be that the major distribution area of the CTIB is far away from the EQ's epicenter on the edge of the basin. Characteristics of the RPS series evolution show that the EQ onset times are 4-8 days apart from (before or after) the maximum wave peaks. To explain the relationships between EQs and CTIBs in petroliferous basins, we have proposed a basin warming effect model.

\subsection{Basin Warming Effect Model}

3.3.1 Relationship between basin type and CTIB characteristics The CTIBs analyzed here were related to six EQs that occurred around four petroliferous basins (Table 1). The western Sichuan basin is rich in oil and gas, which indicates the possibility of a CTIB or warming effect if leaking occurs during seismic stress loading. The CTIB anomalies show many similarities, as shown in Figure 5a and $5 \mathrm{~b}$. The coincidence of anomaly and earthquake in such a setting may be related to the basin's warming effect. Before the two western Sichuan EQs, the basin was loading by stress coming from a geological block of the Qinghai-Tibet Plateau. Such stress increases micro-cracks in the crust, providing channels for gas leakage. The outflow and accumulation of greenhouse gases such as $\mathrm{CH}_{4}$ and $\mathrm{CO}_{2}$ above the surface of the earth in such settings can have a significant radiation warming effect (Anderson et al., 2017), resulting in characteristic earth surface thermal radiation anomalies before earthquake events (Lombardo et al., 2009; Jiao ZH et al., 2018).

Compared to the western Sichuan basin, the Tarim basin is also a 

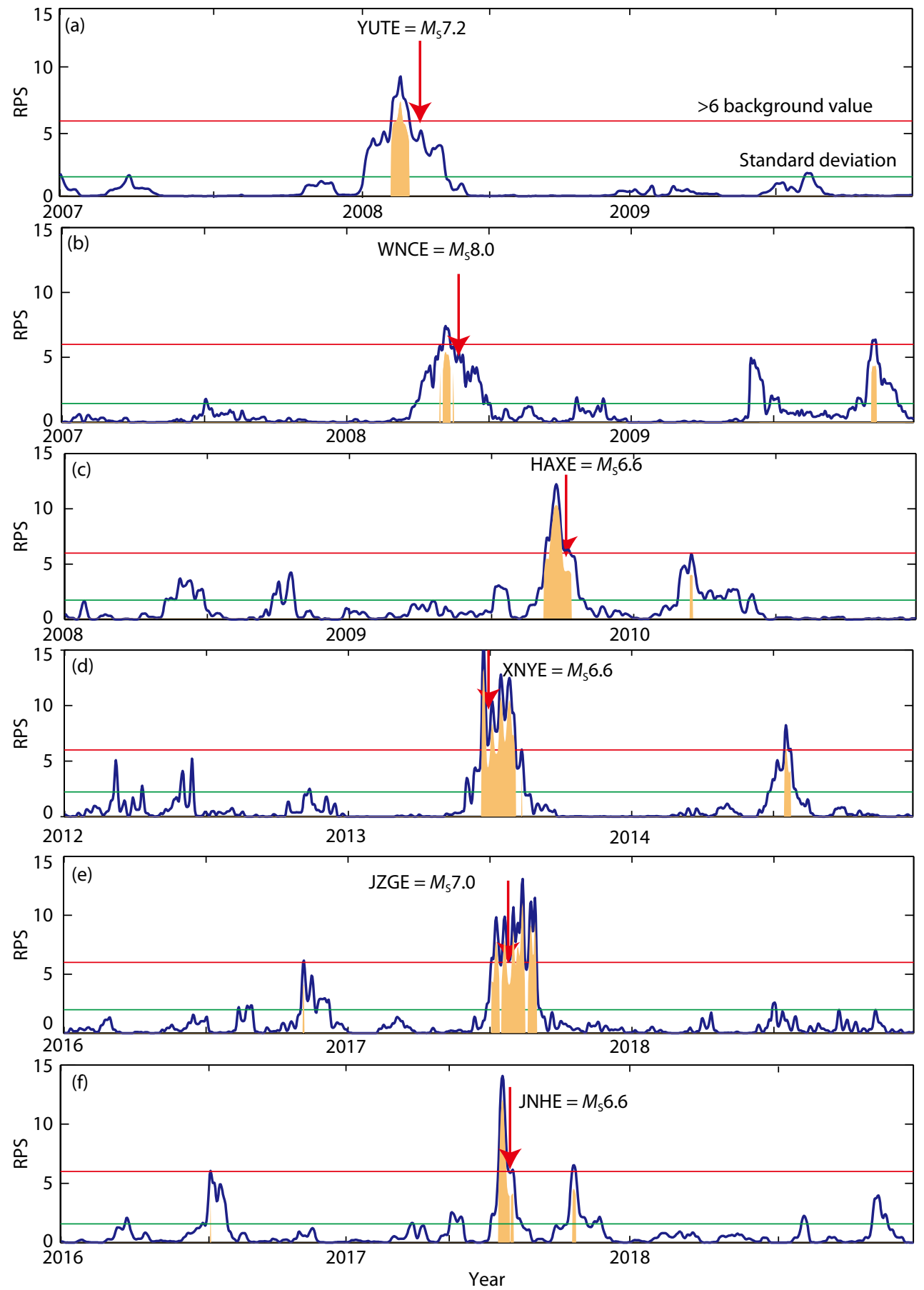

Figure 6. Three years' time series curves of the RPS of six EQs. The blue curve shows the RPS in the 3-year periods before and after of the EQ, and the red line indicating RPS $=6$ is used as demarking the significance level. Then any areas in which values of RPS $>6$ are filled with yellow color.

petroliferous basin that has strong tectonic deformation in its periphery. Under regional stress loading, the structure system along the edge of the basin becomes a good channel for the upwelling of underground gas. Especially following these strong EQs, the response of the basin to the stress changes is active for its underground gas storage, capable of causing the oil and gas to escape and then causing a warming phenomenon in the low-altitude atmosphere. This phenomenon may explain the CTIB anomalies observed in a large area of the basin so far. Similarly, the Junggar basin and Qaidam basin also have abundant petroleum resources. Thus, changes in the mechanical environment related to the JNHE and HAXE could lead to CTIB anomalies also in those basins.

Considering the results of previous studies (Tronin, 2009; Zhang YS et al., 2010; Xie T and Ma WY, 2015; Cui Y et al., 2017; Jiao ZH et al., 2018), we conclude that the evolution of CTIB anomalies with time may be related to the process of stress accumulation. First, the areas of thermal radiation anomalies co-seismic with these earthquakes were all observed to reach more than $50 \%$ of the areas of the basin (Table 1), among which those of YUTE and JNHE 
rose up to $100 \%$. It seems that the larger the abnormal area, the higher the areal ratio of a co-seismic anomaly in the basin. This phenomenon may show that a large amount of oil and gas in the underground region of a petroliferous basin is more sensitive to the stress change following an EQ. Second, when seismic stress is accumulated to a certain extent, active tectonic belts and some micro-fissures on the periphery of the basin are all creating upwelling channels of gas, resulting in effects of $\mathrm{CH}_{4}, \mathrm{CO}_{2}$, and other greenhouse gases on radiative warming. Finally, after the $E Q$, energy-release and stress adjustment appear to change slowly to a new equilibrium state. The abnormality of the thermal radiation after the EQ continues for a period, reflecting this process of gradual stress adjustment to the new state. In these petroliferous basins, the continuous increase under stress leads to an increase in escaping gases and CTIBs. The CTIB anomalies observed in different basins show some similarities: in area proportions, in area size, and in location of the whole basin.

Thermal infrared anomalies were not observed during every earthquake in the study area. In particular, no thermal anomaly was observed in the cases of two of the eight earthquakes of $M_{\mathrm{S}} \geq$ 6.5 that have been recorded in the Tarim, Junggar, and Sichuan basins. If we select $M_{\varsigma} 6.5$ to be the threshold above which a coseismic thermal infrared anomaly can be expected, that threshold appears generally reasonable. However, it cannot be expected to predict a one-to-one match. Not every large earthquake in such settings will be associated with a CTIB. We suggest that the major reason is that the basins are large and not all of these EQs occur near the basins' oil/gas reservoirs. Besides, the catalogs of earlier earthquakes are not complete, making it difficult to estimate ac- curately their magnitudes and distances from hydrocarbon deposits. That is to say, we can't predict at this time exactly how big an earthquake must be in these basins to produce thermal infrared anomalies.

\subsubsection{Modeling the basin warming effect}

Given the discussion above, we propose a model of the basin warming effect (Figure 7). The gas releasing channels in this model include the fault systems and micro-fissures. We suggest that the accumulation of released gas above a basin is bound to be affected by the surrounding terrain, especially mountains, and that the amount of such resistance to dispersion is conducive to the occurrence of the warming process.

These basins are all located around the Qinghai-Tibet Plateau (Figure 7). One of the greatest responses to the uplift of the Qinghai-Tibet Plateau is the increasing altitude of mountains to the east and north, as well as the altitude difference between the mountain and the basin. As shown in Figure 6a, the Tarim basin is located on the northern side of the Qinghai-Tibet Plateau, the Junggar basin is on the northern side of Tarim basin, and in the middle are the Tianshan Mountains (Figure 1b). Besides, the Sichuan basin is located on its eastern side (Figure 1, 7b), and the Qaidam basin is in the southern Qinghai-Tibet Plateau. Similarly, the spatial distribution of the CTIB anomaly in the WNCE is a reference point, and the fact that the anomaly of the Longmenshan fault is at the front of the JZGE may be related to future large EQ development.

On the edge of the basin, the area near the fault is an active re-
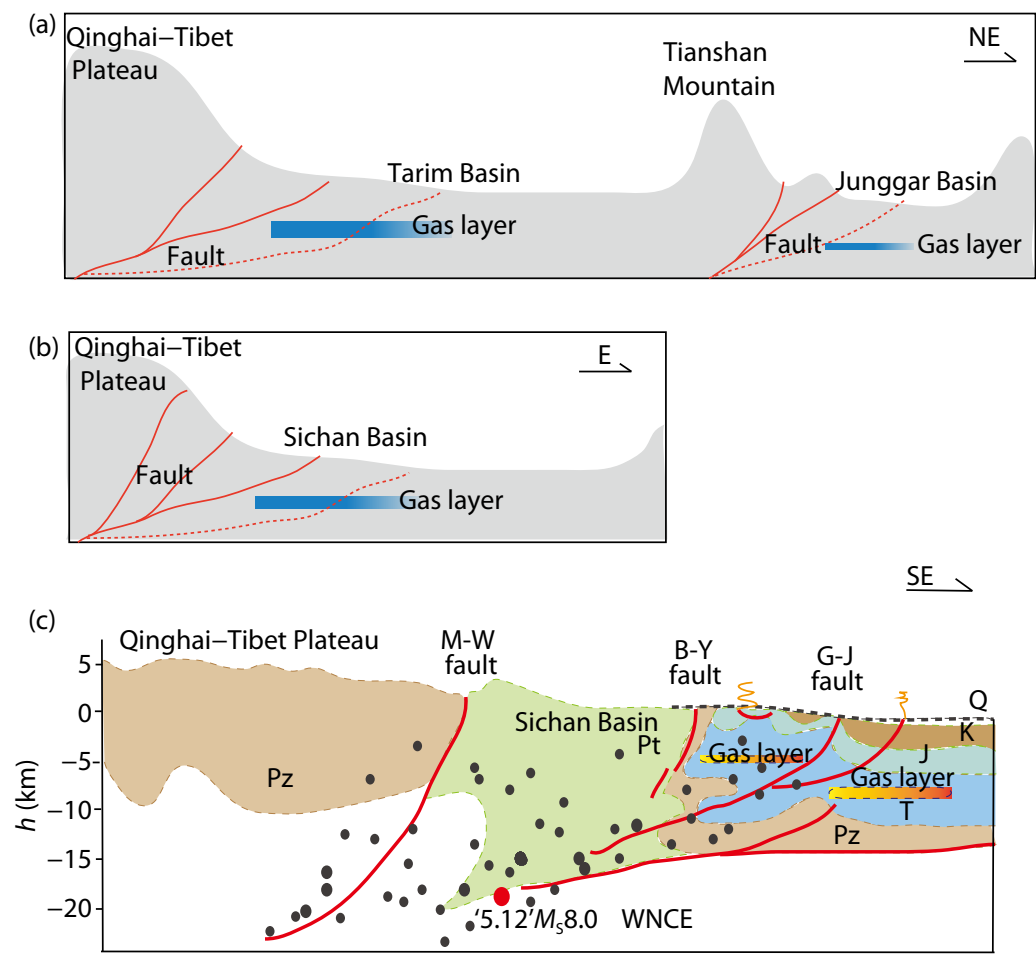

Figure 7. Basin warming effect model. (a) The gas layers are below both of the basins and are not far from the piedmont fault where the EQ occurred. (b-c) The Sichuan basin is located in the eastern Qinghai-Tibet Plateau, in which the phenomenon of a gas layer is similar to that of (a). The difference is the famous Longmenshan fault, which is specifically and accurately distributed in the illustrations (c). 
gion of tectonic activity and gas release. Gases are blocked by the high mountains on one side when the seismic stress causes gases to escape, and it stays in the basin range and accumulates, causing a greenhouse warming effect. The effects of the fluid in fault zones may result in induced seismicity and gas leakage; even the injecting of fluid (to produce oil by "fracking") in a fault zone could cause overpressure and trigger strong EQs (Rinaldi et al., 2014; Lei XL et al., 2019). Typically this kind of EQ occurs in the south of the Sichuan basin (Lei XL et al., 2019). Besides, the research on EQ precursors shows that the underground electric field and the atmospheric electric field will be abnormal (sometimes increasing) before an EQ. Here, we conclude that a holistic and reasonable model is needed to establish a workflow to interpret the leakage of gas.

In this model, the topography between mountains and basin is not conducive to gas emission. According to the simulation result (Gao FL et al., 2012), the thermal infrared wavelength domain in $7.7 \mu \mathrm{m}$ is the advantage absorption range of $\mathrm{CH}_{4}$. In this range, anomalous CTIB at the earth's surface is possible due to the high concentration of $\mathrm{CH}_{4}$ and $\mathrm{CO}_{2}$ in the atmosphere. However, in the thermal infrared wavelength domain, typical absorption bands are induced rapidly if $\mathrm{CH}_{4}$ is mixed at high concentration, such as $3 \mathrm{CH}_{4}$ and $6 \mathrm{CH}_{4}$ as shown in the inset figure of Figure 8. Mountains around the basins obstruct the spread of gases escaping from underground, enhancing the greenhouse effect. For the Sichuan basin, the western part is near the Longmenshan mountains and the Qinghai-Tibet Plateau, and the northern side is the Qinling Mountains (Figure 1). The altitudes of these mountains are all so great (more than $3000 \mathrm{~m}$ ) that they are not conducive to gas emission. Besides, other basins with similar features have been observed to exhibit similar CTIBs. For instance, on the south side of the Tarim basin are the Kunlun Mountains and the Altun Mountains, with average altitudes more than $3000 \mathrm{~m}$. The Junggar basin is located between the Tianshan and Altay Mountains (Figure 1). The Tianshan Mountains located at the southern edge of the basin are at an altitude of over $4000 \mathrm{~m}$. The mountains of both basins block dispersion of gases emitted from underground hydrocarbons released by seismic processes.
An EQ always occurs at the edge of a basin, particularly at the junction of a basin and plateau (Figure 8), such as the Lonmengshan and Altyn Tagh faults, respectively, located at the junctions of the Qinghai-Tibet Plateau to the Sichuan and the Tarim basins. In Figure 8 , a case model reflects a greenhouse gas $\left(\mathrm{CH}_{4}\right)$ leaking into a full petroliferous basin, leading to a CTIB anomaly observed above the basin. For instance, the Tarim basin is very petroliferous, full of gas and oil. However, on the southern edge of the Tarim basin, the Qinghai-Tibet Plateau continues to extrude northward. Once an EQ begins developing or is occurring at any random point in time, $\mathrm{CH}_{4}$ or other greenhouse gases can escape and form CTIB anomalies along the fault pathway of the basin. The topographic effect of the basin, however, cannot be ignored. The basins are surrounded by very high mountains on three sides, indicating that a large amount of gas accumulation can lead to an enhanceds greenhouse effect and CTIB anomalies, such as in the Tarim basin and Sichuan basin after big EQs. As was reported by Lu X et al. (2016), variations in the 8-day CO total column show that the values of CO measured before and after the 2010 Yushu $M_{\mathrm{s}} 7.1 \mathrm{EQ}$ were higher than the previous two-year average. In the petroliferous basins considered herein, the leakage of $\mathrm{CH}_{4}$ and $\mathrm{CO}_{2}$ will be larger when an earthquake occurs than during normal times (Cui $Y$ et al., 2017). In the active fault of the basin's edge, the leakage of $\mathrm{CH}_{4}$ and $\mathrm{CO}_{2}$ is consistent with the intensity of regional tectonic activity (Chen $\mathrm{Z}$ et al., 2019a, b).

Satellites remotely focus on heat emissions and can sense the greenhouse effect in the basins. Sand and desert covering the basin areas surrounded by high mountains make it possible to detect surface thermal anomalies in remotely sensed observations. Gas leakage can explain a strong CTIB anomaly. However, satellite remote sensing covers giant areas, including cloudy areas as well as the land surface. Thus, only in ideal conditions (very low cloud cover) will be possible to detect the strongest CTIB anomalous signals that we suggest will accompany earthquakes.

An aspect missing from previous research on this topic (Blackett et al., 2011; Saradjian and Akhoondzadeh, 2011; Qin K et al., 2012; Akhoondzadeh, 2012, 2014) is a statement on the less obvious relationship between the different geological settings and their cor-

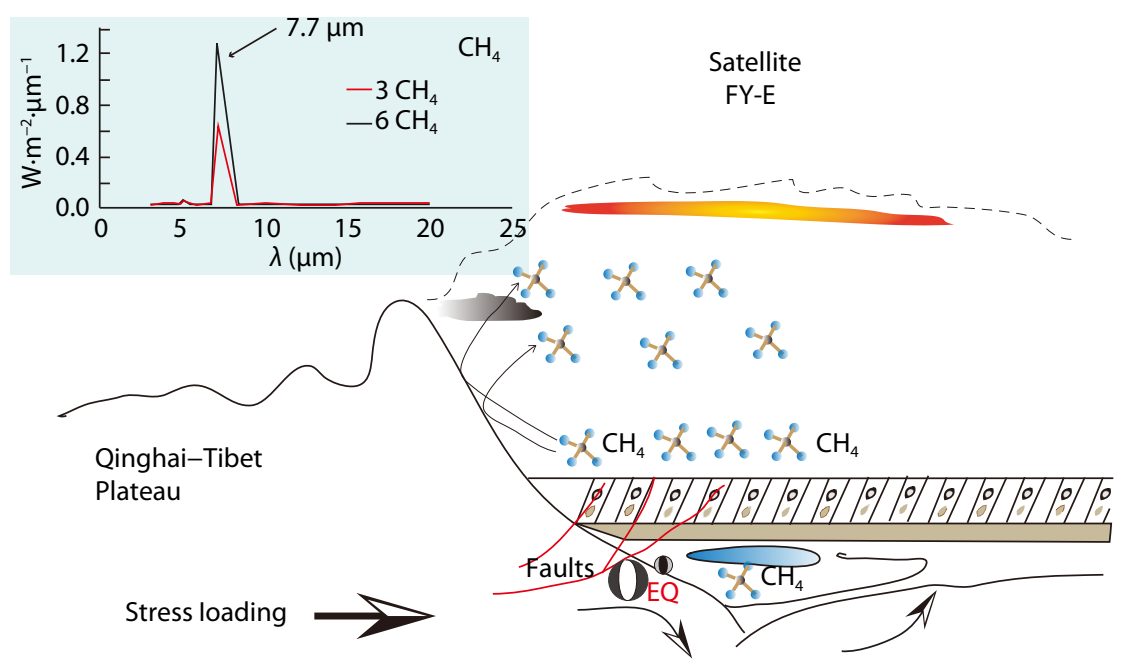

Figure 8. Greenhouse gas leaking in the petroliferous basin under the extrusion of the Qinghai-Tibet Plateau. 
responding CTIB anomalies. Another highlight of the current study is that the magnitudes and distributions of the co-seismic heat radiation anomalies reported were different from those that were possibly influenced by the Kuroshio Sea's current fluctuations, gas emissions, or increasing snow surface temperatures. In this study, we have attempted to explore a pattern between the CTIB anomalies and geological settings based on observing a definite correlation between basins and CTIBs. However, the anomalies show similar values in similar petroliferous basins' settings, and they can display similar distributions in different EQ structure settings. Thus, we suggest that a basin effect model can explain the detection of co-seismic anomalous geophysical signals during six EQs, after considering CTIB anomalies in the basins of western China.

An important aspect of this discussion is the basin warming effect, which may be a new interpretation of seismic relative thermal radiation anomalies on petroliferous basins. Previous studies have shown that the abnormality of thermal radiation during EQs is related to basins with abundant geothermal resources, which is an active point in seeking the true cause and mechanism of the CTIB anomalies. The research of Qiang ZJ et al. (1994, 1999), for example, showed that there was a good correspondence between the oil and gas accumulation zone and the CTIB anomalous region during the EQ; Colacino and Conte (1993) suggested that the concentration of $\mathrm{CH}_{4}$ was more than two times higher than the average value in the low-altitude atmosphere before the $E Q$, where the concentration of $\mathrm{CO}_{2}$ was 2.6 times higher than the average value. Through a long period of observation, using the same approaches to the processing of long-term data, researchers arrived at similar results around the Qinghai-Tibet Plateau (Lu ZQ et al., 2005; Guo WY et al., 2006; Zhang YS et al., 2010; Xiong P et al., 2015; Xie T et al., 2013; Xie T and Ma WY, 2015; Bhardwaj et al., 2017b). They also suggested that the warming effect might be related to seismogenic mechanisms; however, this is relevant only if the geological conditions and basin topography allow the gases to gather, which results in the gases being released to form a CTIB anomaly. Besides, with the absence of greenhouse gases escaping in the Junggar basin's faults and the west Sichuan basin (Cui $Y$ et al., 2017; Chen Z et al., 2019a, b), fewer gases are escaping before EQs in other basins if these basins are without gas reservoirs.

On the one hand, the model interprets the CTIB anomaly spatial distribution as similar to the distribution in basins with substantial oil and gas resources. On the other hand, the proportion of abnormal areas of thermal radiation is concentrated on the edge of similar basins, such that basin terrain factors must be taken into consideration. The evolution of the topographic effect of basins on other physical processes is widely studied (Choudhury et al., 2006; Brański, 2009), including the greenhouse effect of the basin. Guo WY et al. (2006) concluded that a CTIB anomaly appeared in the northwestern margin of the Tarim basin before the Bachu $M_{s} 6.8 \mathrm{EQ}$ in 2003. Ma WJ et al. (2015), also, reported a CTIB anomaly before the Lushan $M_{S} 7.0 \mathrm{EQ}$ in 2010, in which the epicenter of the Lushan EQ was located along the western edge of the Sichuan basin. They found that the spatiotemporal evolution of the air temperature anomaly increased in the Sichuan basin, owing to the air temperature anomaly of a periodic tidal force. We intro- duce a basin model that we have developed to explain the occurrence of CTIB anomalies. To some extent, it is possible to suggest that undetected CTIB anomalies may have occurred before and after some large EQs. Overall, the research can be summarized as follows: two conditions necessary for the occurrence of a CTIB anomaly associated with an earthquake are (1) abundant oil and gas resources near the seismogenic structure and (2) terrain conditions that are favorable for the accumulation of greenhouse gases.

\section{Conclusion}

In this work, we studied the similarities among the co-seismic thermal infrared brightness anomalies (CTIB) around earthquakes in petroleum basins surrounding the Qinghai-Tibet Plateau. Through analysis of six cases, we found that the observed brightness anomalies were present before, during and after earthquakes $\left(M_{\mathrm{S}}>6.5\right)$ and could cover from $50 \%$ to $100 \%$ of the basin area. To explain the identified similarities, a basin warming effect model was developed, based on geography and the petroliferous nature of the basins. The basin effect model posits that, before and during earthquakes, greenhouse gases leak from reservoirs beneath these petroleum basins through faults and microcracks. However, it remains to be studied further how the gas leakage could result in CTIB anomalies only in the basin's particular terrain conditions. We suggest that remote sensing is a good monitoring method to allow further study of the CTIB anomalies caused by gas leakage in petroleum basins and non-petroleum basins.

\section{Acknowledgments}

We thank Prof. Yuansheng Zhang for providing CTIB data analysis and calculation software. The work is supported by the research project of China Earthquake Administration - Earthquake Science and Technology Star Fire Plan (XH2018035Y), and Seismic Regime Tracking Project of CEA (2020010410).

\section{References}

Akhoondzadeh, M. (2012). Anomalous TEC variations associated with the powerful Tohoku earthquake of 11 March 2011. Nat. Hazards Earth Syst. Sci., 12(5), 1453-1462. https://doi.org/10.5194/nhess-12-1453-2012

Akhoondzadeh, M. (2014). Thermal and TEC anomalies detection using an intelligent hybrid system around the time of the Saravan, Iran, $\left(M_{\mathrm{w}}=7.7\right)$ earthquake of 16 April 2013. Adv. Space Res., 53(4), 647-655. https://doi.org/10.1016/j.asr.2013.12.017

Aliano, C, Corrado, R., Filizzola, C., Genzano, N., Pergola, N., and Tramutoli, V. (2008). Robust TIR Satellite techniques for monitoring earthquake active regions: limits, main achievements and perspectives. Ann. Geophys., 51(1), 303-318. https://doi.org/10.4401/ag-3050

Anderson, J. S., Romanak, K. D., Yang, C., Yang, C. B., Lu, J. M., Hovorka, S. D., and Young, M. H. (2017). Gas source attribution techniques for assessing leakage at geologic $\mathrm{CO}_{2}$ storage sites: Evaluating a $\mathrm{CO}_{2}$ and $\mathrm{CH}_{4}$ soil gas anomaly at the Cranfield $\mathrm{CO}_{2}$-EOR site. Chem. Geol., 454, 93-104. https://doi.org/10.1016/j.chemgeo.2017.02.024

Bhardwaj, A., Singh, S., Sam, L., Joshi, P. K., Bhardwaj, A., Martín-Torres, F. J., and Kumar, R. (2017a). A review on remotely sensed land surface temperature anomaly as an earthquake precursor. Int. J. Appl. Earth Observ. Geoinform., 63, 158-166. https://doi.org/10.1016/j.jag.2017.08.002

Bhardwaj, A., Singh, S., Sam, L., Bhardwaj, A., Martín-Torres, F. J., Singh, A., and Kumar, R. (2017b). MODIS-based estimates of strong snow surface temperature anomaly related to high altitude earthquakes of 2015. Remote 
Sens. Environ., 188, 1-8. https://doi.org/10.1016/j.rse.2016.11.005

Blackett, M., Wooster, M. J., and Malamud, B. D. (2011). Exploring land surface temperature earthquake precursors: a focus on the Gujarat (India) earthquake of 2001. Geophys. Res. Lett., 38(15), L15303. https://doi.org/10.1029/2011GL048282

Brański, P. (2009). Influence of palaeoclimate and the Green House effect on Hettangian clay mineral as sem blages (Holy Cross Mts. area, Polish Basin). Geol. Quart., 53(3), 363-368.

Chen, Z., Li, Y., Liu, Z. F., Zheng, G. D., Xu, W., Yan, W., and Yi, L. (2019a). $\mathrm{CH}_{4}$ and $\mathrm{CO}_{2}$ emissions from mud volcanoes on the southern margin of the Junggar basin, NW China: Origin, output, and relation to regional tectonics. J. Geophys. Res.: Solid Earth, 124(5), 5030-5044. https://doi.org/10.1029/2018JB016822

Chen, Z., Li, Y., Liu, Z. F., Lu, C., Zhao, Y. X., and Wang, J. (2019b). Evidence of multiple sources of soil gas in the Tangshan fault zone, North China. Geofluids, 2019, 1945450. https://doi.org/10.1155/2019/1945450

Choudhury, S., Dasgupta, S., Saraf, A. K., and Panda, S. (2006). Remote sensing observations of pre-earthquake thermal anomalies in Iran. Int. J. Remote Sens., 27(20), 4381-4396. https://doi.org/10.1080/01431160600851827

Colacino, M., and Conte, M. (1993). Greenhouse effect and pressure patterns in the Mediterranean basin. IL Nuovo Cimento C, 16(1), 67-77. https://doi.org/10.1007/BF02509211

Corrado, R., Caputo, R., Filizzola, C., Pergola, N., Pietrapertosa, C., and Tramutoli, V. (2005). Seismically active area monitoring by robust TIR satellite techniques: a sensitivity analysis on low magnitude earthquakes in Greece and Turkey. Nat. Hazards Earth Syst. Sci., 5(1), 101-108. https://doi.org/10.5194/nhess-5-101-2005

Cui, Y., Ouzounov, D., Hatzopoulos, N., Sun, K., Zou, Z., and Du, J. (2017). Satellite observation of $\mathrm{CH}_{4}$, and $\mathrm{CO}$ anomalies associated with the Wenchuan $M_{S} 8.0$ and Lushan $M_{S} 7.0$ earthquakes in China. Chem. Geol., 469 , 185-191. https://doi.org/10.1016/j.chemgeo.2017.06.028

Filizzola, C., Pergola, N., Pietrapertosa, C., and Tramutoli, V. (2004). Robust satellite techniques for seismically active areas monitoring: a sensitivity analysis on September 7, 1999 Athens's earthquake. Phys. Chem. Earth Parts A/B/C, 29(4-9), 517-527. https://doi.org/10.1016/j.pce.2003.11.019

Gao, F. L., Hua, Z. Z., Tao, L. R., et al. (2012). Comparative analysis of greenhouse effect of methane and carbon dioxide. Chinese Society of Engineering Thermophysics, http://ir.etp.ac.cn/handle/311046/58867

Guo, W. Y., Shan, X. J., and Qu, C. Y. (2006). Correlation between infrared anomalous and earthquakes in Tarim basin. Arid Land Geogr. (in Chinese), 29(5), 736-741. https://doi.org/10.3321/j.issn:1000-6060.2006.05.020

Jiao, Z. H., Zhao, J., and Shan, X. J. (2018). Pre-seismic anomalies from optical satellite observations: A review. Nat. Hazards Earth Syst. Sci., 18(4), 1013-1036. https://doi.org/10.5194/nhess-18-1013-2018

Lei, X. L., Wang, Z. W., and Su, J. R. (2019). Possible link between long-term and short-term water injections and earthquakes in salt mine and shale gas site in Changning, south Sichuan basin, China. Earth Planet. Phys., 3(6), 510-525. https://doi.org/10.26464/epp2019052

Lombardo, V., Harris, A. J. L., Calvari, S., and Buongiorno, M. F. (2009). Spatial variations in lava flow field thermal structure and effusion rate derived from very high spatial resolution hyperspectral (MIVIS) data. J. Geophys. Res. Solid Earth, 114(B2), B02208. https://doi.org/10.1029/2008JB005648

Lu, X., Meng, Q. Y., Gu, X. F., Zhang, X. D., Xie, T., and Geng, F. (2016). Thermal infrared anomalies associated with multi-year earthquakes in the Tibet region based on China's FY-2E satellite data. Adv. Space Res., 58(6), 989-1001. https://doi.org/10.1016/j.asr.2016.05.038

Lu, Z. Q., Wu, B. H., Qiang, Z. J., and Du, L. T. (2005). Brightness temperature anomalies in satellite-based thermal infrared remote sensing along the offshore China Seas. Geoscience (in Chinese), 19(1), 74-82. https://doi.org/10.3969/j.issn.1000-8527.2005.01.011

Ma, W. J., Kong, X. Z., Kang, C. L., Zhong, X. H., Wu, H. Y., Zhan, X. S., and Joshi, M. (2015). Research on the changes of the tidal force and the air temperature in the atmosphere of Lushan (China) $M_{\mathrm{s}} 7.0$ earthquake. Therm. Sci., 19(S2), 487-493. https://doi.org/10.2298/TSCI150403148M

Ouzounov, D., and Freund, F. (2004). Mid-infrared emission prior to strong earthquakes analyzed by remote sensing data. Adv. Space Res., 33(3), 268-273. https://doi.org/10.1016/S0273-1177(03)00486-1

Pergola, N., Aliano, C., Coviello, I., Filizzola, C., Genzano, N., Lacava, T., Lisi, M., Mazzeo, G., and Tramutoli, V. (2010). Using RST approach and EOS-MODIS radiances for monitoring seismically active regions: a study on the 6 April 2009 Abruzzo earthquake. Nat. Hazards Earth Syst. Sci., 10(2), 239-249. https://doi.org/10.5194/nhess-10-239-2010

Piroddi, L., Ranieri, G., Freund, F., and Trogu, A. (2014). Geology, tectonics and topography underlined by L'Aquila earthquake TIR precursors. Geophys. J. Int., 197(3), 1532-1536. https://doi.org/10.1093/gji/ggu123

Qiang, Z. J., Dian, C. G., Huang, F. L., and Zhao, Y. (1994). A new method for searching oil by using satellite thermal infrared detection. Chin. Sci. Bull. (in Chinese), 39(18), 1725-1726.

Qiang, Z. J., Dian, C. G., Li, L. Z., Xu, M., Ge, F. S., Liu, T., Zhao, Y., and Guo, M. H. (1999). Satellitic thermal infrared brightness temperature anomaly image-short-term and impending earthquake precursors. Sci. China, 42(3), 313-324. https://doi.org/10.1007/BF02878968

Qin, K., Wu, L. X., De Santis, A., and Cianchini, G. (2012). Preliminary analysis of surface temperature anomalies that preceded the two major Emilia 2012 earthquakes (Italy). Ann. Geophys., 55(4), 823-828. https://doi.org/10.4401/ag-6123

Rawat, V., Saraf, A. K., Das, J., Sharma, K., and Shujat, Y. (2011). Anomalous land surface temperature and outgoing long-wave radiation observations prior to earthquakes in India and Romania. Nat. Hazards, 59(1), 33-46. https://doi.org/10.1007/s11069-011-9736-5

Rinaldi, A. P., Jeanne, P., Rutqvist, J., Cappa, F., and Guglielmi, Y. (2014). Effects of fault-zone architecture on earthquake magnitude and gas leakage related to $\mathrm{CO}_{2}$ injection in a multi-layered sedimentary system. Greenhouse Gases Sci. Technol., 4(1), 99-120. https://doi.org/10.1002/ghg.1403

Saradjian, M. R., and Akhoondzadeh, M. (2011). Thermal anomalies detection before strong earthquakes $(M>6.0)$ using interquartile, wavelet and Kalman filter methods. Nat. Hazards Earth Syst. Sci., 11(4), 1099-1108. https://doi.org/10.5194/nhess-11-1099-2011

Saraf, A. K., Rawat, V., Das, J., Zia, M., and Sharma, K. (2012). Satellite detection of thermal precursors of Yamnotri, Ravar and Dalbandin earthquakes. Nat. Hazards, 61(2), 861-872. https://doi.org/10.1007/s11069-011-9922-5

Tronin, A. A. (1996). Satellite thermal survey-a new tool for the study of seismoactive regions. Int. J. Remote Sens., 17(8), 1439-1455. https://doi.org/10.1080/01431169608948716

Tronin, A. A. (2000a). Thermal IR satellite sensor data application for earthquake research in China. Int. J. Remote Sens., 21(16), 3169-3177. https://doi.org/10.1080/01431160050145054

Tronin, A. A. (2000b). Thermal satellite data for earthquake research. In IEEE 2000 International Geoscience and Remote Sensing Symposium. Taking the Pulse of the Planet: The Role of Remote Sensing in Managing the Environment. Honolulu: IEEE. https://doi.org/10.1109/IGARSS.2000.859687

Tronin, A. A. (2009). Satellite remote sensing in seismology. A review. Remote Sens., 2(1), 124-150. https://doi.org/10.3390/rs2010124

Xie, T., Kang, C. L., and Ma, W. Y. (2013). Thermal infrared brightness temperature anomalies associated with the Yushu (China) $M_{\mathrm{s}}=7.1$ earthquake on 14 April 2010. Nat. Hazards Earth Syst. Sci., 13(4), 1105-1111. https://doi.org/10.5194/nhess-13-1105-2013

$\mathrm{Xie}, \mathrm{T}$. , and Ma, W. Y. (2015). Possible thermal brightness temperature anomalies associated with the Lushan (China) $M_{s} 7.0$ earthquake on 20 April 2013. Earthq. Sci, 28(1), 37-47. https://doi.org/10.1007/s11589-014-0106-8

Xiong, P., Shen, X. H., Gu, X. F., Meng, Q. Y., Zhao, L. M., Zhao, Y. H., Li, Y., and Dong, J. Y. (2015). Seismic infrared anomalies detection in the case of the Wenchuan earthquake using bi-angular advanced along-track scanning radiometer data. Ann. Geophys., 58(2), 1-11. https://doi.org/10.4401/ag6706

Zhang, Y. S., Guo, X., Zhong, M. J., Shen, W. R., Li, W., and He, B. (2010). Wenchuan earthquake: Brightness temperature changes from satellite infrared information. Chin. Sci. Bull., 55(18), 1917-1924. https://doi.org/10.1007/s11434-010-3016-8 